\title{
USOS DE LA TIERRA, CONFLICTO Y PODER POLÍTICO EN LA FRONTERA AGRÍCOLA DEL Alto Sinú 1940-1970
}

${ }^{*}$ Historiadora, magister en Historia; doctorando en Ciencias Sociales. Docente Departamento de Humanidades e Idiomas: Universidad de Cartagena.

**Trabajadora Social magister en Historia doctorando en ciencias sociales. Docente Universidad del Sinú.

\author{
LAND USES, CONFLICT AND POLITICAL POWER IN THE \\ AGRICULTURAL BORDER OF ALTO SINÚ 1940-1970
}

Por: Ruth Esther Gutiérrez Meza*

Yubis Stella Seña Vidal**

Recibido: 15 de marzo de 2016 - Aprobado: 29 de julio de 2016

\section{RESUMEN}

El presente artículo presenta un recorrido histórico, a partir del cual aborda las perspectivas historiográficas desde donde se ha estudiado la manera cómo la subregión del alto Sinú se convirtió en una frontera agrícola, que a mediados del siglo XX y más específicamente entre 1940 y 1970 , despertó un profundo interés en las élites económicas y políticas nacionales y regionales, quienes abiertamente iniciaron un proceso de acaparamiento de las tierras e instauración de sistemas laborales que incluían la sujeción de la mano de obra a las corrientes bipartidistas liberales y conservadoras. Así mismo, se presentan las formas contestatarias que adoptaron los campesinos del alto Sinú frente al monopolio de la tierra ostentado por gamonales y funcionarios públicos.

Palabras claves: Alto Sinú, baldíos, sujeción, colono, campesino y poder político.

\begin{abstract}
This article presents a historical journey, from which it addresses the various historiographical perspectives examining the way the sub region called Alto Sinú became an agricultural borderland, which in the mid-twentieth century and, more specifically, between 1940 and 1970, aroused a keen interest in the economic and political national and regional elites, who openly began a process of land grabbing and establishment of labor systems involving the subjection of labor to liberal and conservative bipartisan currents. Likewise, the rebellious peasants from Alto Sinú adopted against the monopoly of land held by bosses and civil servants.
\end{abstract}

Keywords: Alto Sinú, vacant, subject, settler, farmer and political power.

\section{Introducción}

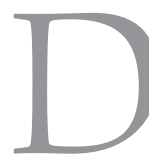

urante el periodo colonial muchos territorios de lo que hoy se conoce cómo la costa Caribe, se mantuvieron aislados de las dinámicas de explotación y mercantilismo impulsadas por la Corona española. Estos se constituyeron en "fronteras internas" a donde no llegó ni la presencia 
del Estado colonial que predominó hasta fines del siglo XVIII, ni la del Estado republicano a lo largo del siglo XIX (Serje, 2005)

El siglo XIX consolidó la imagen de oscuridad y peligro de las fronteras internas y las enmarcó como tierras de promisión. Los llamados "baldíos" no fueron considerados por el Estado y los diferentes gobiernos con visión de largo plazo y menos como proyecto nacional que implicara modernidad y progreso para toda la población, más bien "la política de baldíos fue caótica, incoherente y cambiante, según los intereses de los grupos en el poder" (machado, 2009). Más que una política de Estado, fue un sistema casuístico de los diferentes gobiernos nacionales en acuerdo con las élites regionales, para ofrecer los baldíos como zonas que guardaban tesoros y riquezas naturales de productos renovables y no renovables que garantizaban el progreso y el desarrollo a aquellos que se aventuraran a poseerlas. Es así como la figura del colono aparecerá frecuentemente en varias zonas del país entre ellas el suroeste antioqueño donde se convirtió en un sujeto esencial para la consolidación de los núcleos poblacionales ubicados en las fronteras agrícolas del país (Ramírez y Londoño, 2013). Así mismo, en el Caribe colombiano, más específicamente, en el Alto Sinú el colono figuró como parte fundamental del patrón de poblamiento que avanzaba desde finales del siglo XIX hasta el siglo XX.

El presente artículo presenta cómo la subregión del alto Sinú se convirtió en una frontera agrícola, que en el siglo XX despertó un profundo interés en las élites económicas y políticas nacionales y regionales, quienes abiertamente iniciaron un proceso de acaparamiento de las tierras e instauración de sistemas laborales que incluían la reducción del campesino a simple fuerza de trabajo y la sujeción de esta mano de obra a las corrientes bipartidistas de ese momento. Así mismo, se presentan algunas de las formas contestatarias que adoptaron los campesinos del alto Sinú frente al monopolio de la tierra que un día les perteneció.

Para tal fin, se hace una revisión historiográfica de algunos de los autores, cronistas y viajeros que han dedicado sus investigaciones a dar cuenta de las dinámicas asociadas a este territorio. Es decir, que abordan temas cómo los usos de la tierra, las dinámicas laborales de los campesinos y los conflictos económicos y políticos con los terratenientes, que en este artículo se vuelven piezas fundamentales para dar forma al contexto histórico del Alto Sinú. 


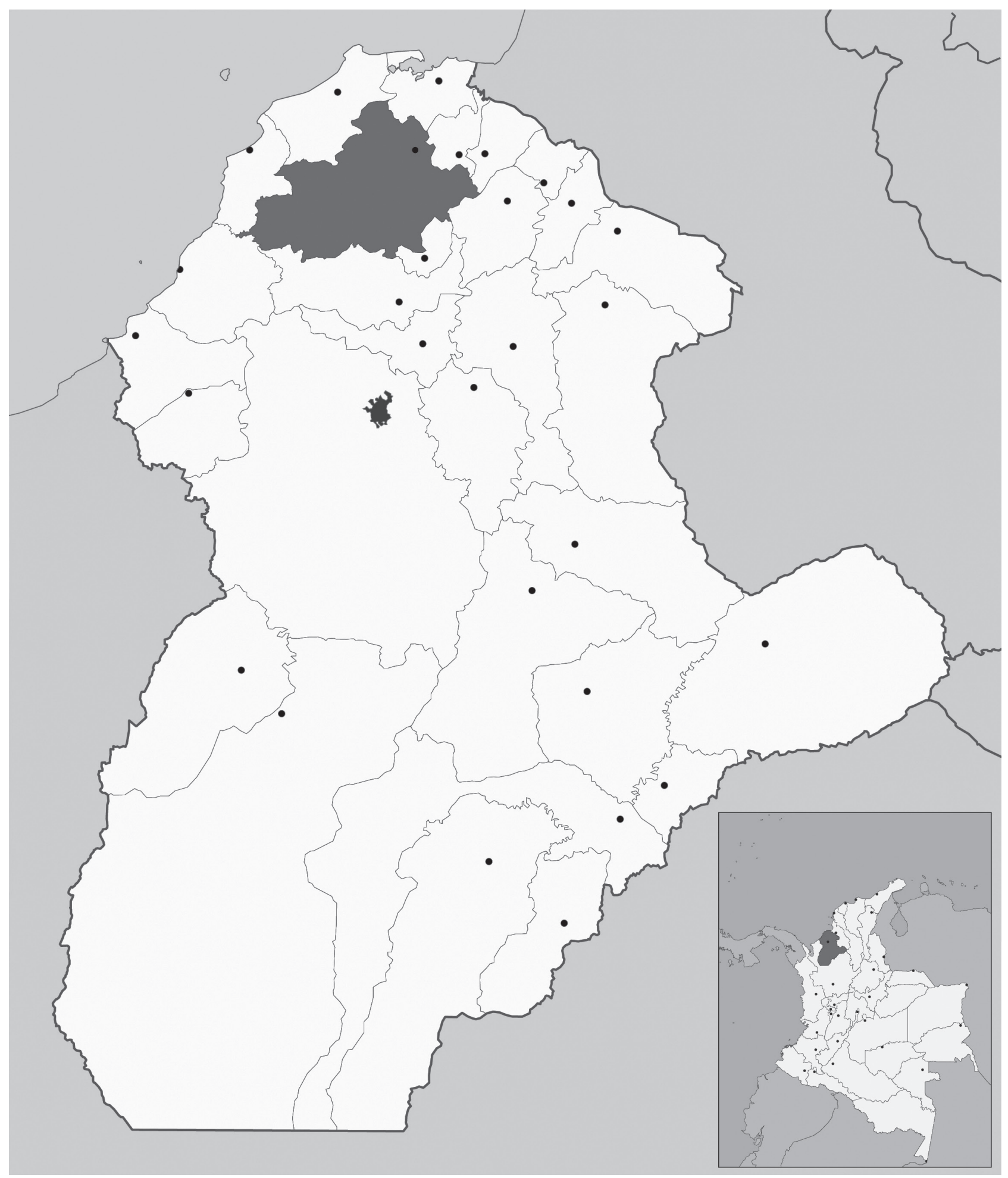

\section{Mapa 1. Ubicación del Alto Sinú.}

Fuente: Instituto Colombiano de Antropologia e Historia (ICANH). "Ubicación del Alto Sinú en Colombia". http:// www.icanh.gov.co/ver_pagina_ingles/release/register_of_archaeological_sites/alto_sinu/ubicacion_alto_sinu_colombia 


\section{La búsqueda de los recursos en el Alto Sinú}

E l departamento de Córdoba, que durante el siglo XIX perteneció al Estado Soberano de Bolívar, se configuró cómo departamento a mediados del siglo XX en medio de tensiones políticas donde los intereses particulares de las élites locales cordobesas jugaron un papel fundamental (Lambis 2015). En la actualidad se encuentra ubicado al noroeste del país, a orillas del Mar Caribe al oriente limita con Sucre y Bolívar, al este con el mar Caribe y el departamento de Antioquia y posee una extensión de 23.980 kilómetros cuadrados; su clima varía, con promedios desde los $280 \mathrm{C}$ en la zona costera hasta los $180 C$ en las zonas altas de la cordillera occidental; el departamento de Córdoba se divide en dos subregiones: La primera, integrada por los municipios del norte y el centro, y la segunda, que es el centro de interés de este estudio, está integrada por los municipios de Tierralta y Valencia, y es conocida como la subregión del Alto Sinú (Arias 2009). El siguiente mapa ilustra dos de los municipios más importantes del Alto Sinú:

El Alto Sinú limita al sur con el Nudo de Paramillo, al este la serranía de San Jerónimo, desde el alto del Paramillo hasta el cerro Murrucucú; al oeste la serranía de Abibe desde el alto del León hasta el alto Quimarí y al norte la angostura de Urrá; es una región montañosa con alturas entre los 100 y los 4000 metros sobre el nivel del mar aproximadamente y una precipitación promedio de 3000 milímetros anuales (Gobernación de Córdoba, 2010).

Esta es una zona montañosa con relieves pertenecientes a las serranías de Abibe, San Jerónimo y Ayapel que son prolongaciones de la cordillera occidental, su suelo es significativamente fértil con una densa vegetación tropical, arboles colosales y bañada por el río que lleva su nombre (Striffler, 2008). El clima se clasifica como de bosque húmedo tropical y bosque muy húmedo tropical, con tierras favorables para la cría de ganado a gran escala. El cronista José Francisco García, quien estuvo en el Alto Sinú a mediados del siglo XX registro algunas de las características climáticas de la zona:

El clima del Alto Sinú es bastante fresco que puede calificarse como templado; en Tucurá, El Verde y La Esmeralda es muy parecido al de Medellín. En ninguna de estas comarcas se consigue el fatídico mosquito que en otras partes tanto perjudica; desde Tierralta hasta la boca del Rio Verde observé que en los lechos de los ríos, junto con las arenas y guijarros, existía oro (...)” (García, 1976). 
Desde la segunda mitad del siglo XIX hasta mediados del siglo XX, las características de esta zona favorecieron la llegada de centenares de colonos en busca de tierras habitables y con recursos naturales renovables y no renovables para su sostenimiento. Durante estos años el Alto Sinú vivió por primera vez la ocupación de su espacio geográfico con fines de explotación, pues durante los años precedentes "no hubo explotación económica, ni ocupación social excepto por la presencia reducida de algunas tribus indígenas y buscadores de copaiba y zarzaparrilla" (Fals, 2002). Ya en el siglo XX el Alto Sinú se pobló alrededor de tres polos: Tucurá, Tierralta y Pueblo Nuevo. El norte de Tucurá fue poblado principalmente por campesinos provenientes de Antioquia. Entre Tucurá y Tierralta al igual que por Río Nuevo, entraron gentes provenientes del Bajo Sinú, de Sabanas y del Magdalena (Escobedo, 2000).

Como lo plantea Freddy Guerrero, el Alto Sinú ha sido una zona proclive al reconocimiento solo en términos de explotación de recursos naturales o mano de obra (Guerrero, 2009). De hecho la subregión del Alto Sinú fue incorporada al sistema capitalista en la segunda mitad del siglo XIX, cuando el gobierno autorizó la ocupación de "baldíos" como medio para despegar la economía nacional (Meisel y Pérez, 2006). A principios del siglo XX, la subregión del Alto Sinú poseía una baja densidad de poblamiento, sin embargo, el gobierno nacional en aras de conectar la economía nacional al mercado mundial impulsó las inversiones internacionales para la explotación de hidrocarburos, maderas, caucho, curtiembres, aceites, entre otros (CINEP, 1998).

Además de los municipios de Tierralta y Valencia, también se encuentran, Juan José, Montelíbano, Uré y Tucurá. Todos ellos fueron en la segunda mitad del siglo XIX territorios baldíos a los que llegaron colonos que se convirtieron en campesinos que cultivaban la tierra y construían tradiciones culturales a partir de su interacción con el ecosistema que los rodeaba. Durante su viaje a la subregión del Alto Sinú en el año de 1844 el alemán Luis Striffler registró su percepción sobre el territorio:

"En las pocas matas de plátano ya cultivadas en las inmediaciones del rancherío, vi la prueba palpable de la feracidad del terreno. En ninguna parte del litoral (de Córdoba) se nota una energía igual en la vegetación. Todo, plantas y frutas, tiene un volumen triple de los más corpulentos de la misma especie que había visto hasta entonces. El maíz y el arroz presentan el mismo lujo vegetativo. Además de la fecundidad natural del suelo, hay todavía la ventaja de que en aquellas 
regiones elevadas no se experimenta sequedad en ninguna estación del año, y las cosechas se siguen sin interrupción"(Striffler, 2008).

Striffler resalta en el anterior fragmento una visión del territorio desde la misticidad, es decir, se muestra la imagen de un espacio de ensueño, con riquezas naturales potenciales abiertas a aquellos aventureros que quieran poseerlas. Los poseedores tendrían libertad para imponer sus leyes y primar sus intereses. De este modo una lluvia de empresas privadas y poderes locales se interesarían más tarde por tomar parte en los procesos colonizadores de la frontera agrícola del Alto Sinú. En la segunda mitad del siglo XIX, se adelantaron en Colombia varias inversiones de compañías extranjeras que, en el caso del Alto Sinú, emprendieron la explotación de maderas en los bosques que circundaban el río Sinú (Ocampo, 2007). Estas inversiones extranjeras funcionaron bajo la modalidad de economías de enclave, entendiendo este concepto como lo plantea Orlando Fals Borda, es decir:

La explotación de recursos naturales y humanos en un lugar relativamente alejado según formas de trabajo y técnicas que quedan subordinadas a las relaciones de intercambio que se establecen entre el enclave y el capital extranjero en países originarios o dominantes. En los enclaves se articula la producción directa de la tierra a mecanismos de circulación regional e internacional, se proletariza al trabajador rural, y se crean niveles de desarrollo desigual que pueden llevar poco a poco a la sociedad local al modo de producción capitalista en formas dependientes (Fals, 2002).

El enclave, por su propia naturaleza, no permitió que se generara infraestructura o actividades urbanas y tampoco se impulsó el desarrollo integral regional (Serje, 2005). La historia de esta región y su relación con los proyectos nacionales de "modernidad y progreso", remite a un entramado donde intervienen las empresas privadas y públicas, y los colonos convertidos en campesinos y mano de obra que labora bajo regímenes de explotación. En ese sentido, los gobiernos han dado vía libre a los proyectos y megaproyectos que proponen articular los "baldíos" a la nación, mediante su vinculación a formas de "organización social y espacial" no reguladas por el Estado (Serje, 2005).

En el Alto Sinú este modelo económico entró en vigencia a partir de la explotación de madera, caucho y oro que hicieron compañías francesas y norteamericanas. El caso de Luis Striffler se ubica en el contexto de la 
apropiación de estas tierras por parte de la compañía francesa del Alto Sinú, mostrándose la apertura de esa frontera agrícola a los intereses extranjeros (Striffler, 2008).

La "apertura" del Alto Sinú a fundaciones poblacionales se inició con fines de explotación aurífera y maderera, sin embargo, la presencia de un suelo abundantemente fértil, condiciones climáticas favorables y la llegada de la colonización antioqueña años más tarde hizo posible que el Alto Sinú adquiriera una significativa importancia como frontera agrícola; a partir de allí, la riqueza en recursos naturales dio paso a la aparición de la hacienda y la ganadería como negocio a gran escala. Striffler relata la primera colonización del Alto Sinú impulsada por la compañía francesa de la siguiente manera:

"Había un entusiasmo extraordinario entre toda esa gente llamada a fundar una colonia que se suponía de un inmenso porvenir; todo se hacía con el ardor de la esperanza. Los hacheros cantaban y trabajaban; otros recogían materiales para las casas (.....) iCuantas brillantes utopías nos alumbraban con sus reflejos engañadores! Toda esa soledad debía pronto mudar de aspecto. Grandes poblaciones debían pronto utilizar tantas riquezas naturales. Cada uno de nosotros ya tenía escogido un punto propio para fundar una hacienda en que él solo mandaría como dueño y señor". (Striffler, 2008).

La ocupación inicial de esta fértil frontera dio paso a la fundación de poblaciones de colonizadores que compartían la esperanza de llegar a poseer títulos de propiedad sobre las tierras que diariamente trabajaban. La invitación del Estado a colonizar la zona virgen del Alto Sinú, fue percibida por los recién llegados como la garantía de la titularidad sobre las propiedades que habitaban, pero de las cuales no poseían documentos legales.

En cuanto al impacto de las empresas extranjeras que llegaron a explotar los recursos naturales, el resultado no fue alentador, pues no alcanzaron el umbral del éxito que se habían propuesto en el Alto Sinú, y al final abandonaron el proyecto; no obstante, la tierra jamás volvió a ser la misma. Lejos de cumplir los designios de Striffler, quien argumentó a su salida del Alto Sinú que este había vuelto a "su estado primitivo en que lo habíamos encontrado" (Striffler, 2008). En realidad la intromisión de estas primeras empresas abrió una brecha en la subregión y en sus habitantes que jamás pudo ser cerrada. Este camino abierto trajo consigo la desmembración de las familias nativas 
y la pérdida de la riqueza natural y cultural construida bajo la perceptible relación hombre-tierra.

En su lugar aparecieron centenares de colonos desplazados de las regiones aledañas, y que deambulaban en búsqueda de nuevas oportunidades y la posibilidad de adquirir títulos de propiedad sobre la tierra. En el año 2011 la prensa nacional representada en el periódico El Espectador describió el escenario histórico de la geografía Sinú, en los siguientes términos:

"Entre su extensa llanura, ecosistema de ríos o ciénagas y ariscas ramificaciones de la Cordillera Occidental, el departamento de Córdoba guarda una dolorosa historia de cómo los violentos han querido imponer la ley en su pródigo territorio. Desde mediados del siglo XIX, cuando se empezaron a desarrollar grandes haciendas ganaderas y surgieron los primeros conflictos con colonos, arrendatarios y jornaleros, esta región del país ha vivido una sucesión de guerras que han dejado la memoria de un Estado ausente e innumerables víctimas" (El Espectador, 15.01.2011).

Es en ese sentido, que el presente análisis cobra importancia ya que profundiza en el interés sobre la explotación de los recursos naturales y los conflictos que se generaron a partir de la tenencia de la tierra en el Alto Sinú. El impulso que el gobierno le dio a la utilización de los baldíos pareció, en primera instancia, favorecer a los campesinos o colonos desplazados por la explotación y monopolio de las tierras en las que trabajaban, sin embargo, lo que se observó fue la posterior usurpación de las propiedades indígenas y campesinas por parte de los terratenientes que llegaron tardíamente a esta zona con el fin de apropiarse de los recursos de los suelos fértiles del Alto Sinú para establecer sus haciendas y criar sus ganados, relegando a los colonos iniciales y a los campesinos a una mera mano de obra semiservil que poco se beneficiaba de las significativas ganancias que producían las grandes haciendas agrícolas y ganaderas.

\section{El trabajo hacendil y los usos de la tierra en el Alto Sinú.}

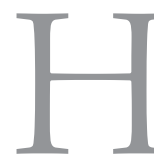

asta este punto se ha planteado cómo la segunda mitad del siglo XIX es el período en que las empresas de carácter privado se apoderan de la tierra en el Alto Sinú, trayendo consigo sistemas laborales basados en la economía de enclave y la mano de obra semiservil. En este aparte se mostrará cómo la propiedad sobre la tierra se convirtió en un elemento fundamental ubicada en el seno de los conflictos sociales, políticos y económicos del siglo 
XX en esta subregión. Desde la actualidad las crónicas periodísticas recogen la dinámica histórica de la siguiente manera:

"Ya entrado el siglo XX, con la presencia creciente de empresarios nativos y antioqueños, interesados en adquirir tierras para levante de ganado y explotación de madera y caucho, los conflictos agrarios comenzaron a adquirir matices ideológicos. Eran los años 20 y con el protagonismo de la Sociedad de Obreros y Artesanos de Montería, entre otras organizaciones, la lucha entre propietarios y ocupantes de predios se saldó escriturando tierras a los campesinos ubicados en zonas adyacentes a los ríos Sinú y San Jorge" (El Espectador.15.01.2011).

Las grandes empresas extranjeras fracasaron en su búsqueda de metales preciosos en el Alto Sinú, sin embargo, dejaron a su paso centenares de kilómetros de bosques derrumbados y explotados que se fueron transformando en unidades productivas conocidas como haciendas agrícolas y ganaderas (Fals, 2002). Tales unidades productivas se convirtieron en capital de riqueza, lo que trajo como consecuencia la aparición de conflictos agrarios entre los acaparadores de tierras y los campesinos que desde finales del siglo XIX se habían trasladado a estas tierras para fundar los primeros asentamientos en las tierras vírgenes del Alto Sinú.

Con la conquista del "bravo y salvaje" bosque del Alto Sinú a cargo de los primeros colonizadores en busca de oportunidades, los terratenientes se interesaron por estas tierras y advirtieron la riqueza en recursos naturales de los que podían apoderarse; de esta manera, favorecidos por las leyes sobre baldíos en Colombia, atrajeron una gran cantidad de mano de obra para que quemase y talase los bosques, y así consolidar la apertura de la frontera. Podría decirse, que este momento coyuntural fracturó los intentos de apropiación de la tierra por parte de los colonizadores iniciales que venían de manera errante buscando tierras que les proporcionaran la estabilidad que habían perdido. La historiografía sobre el tema narra esta dinámica en los siguientes términos:

"grandes espacios derrumbados de selva se fueron transformando en haciendas en manos de otros, al cumplirse la "ley de tres pasos": primero el colono trabajador y productor, segundo el finquero comprador de mejoras; y por último el hacendado que consolida lotes y monopoliza la tierra"(Fals, 2002). 
Como se presenta en el fragmento anterior, rápidamente y gracias a la ausencia del Estado, este territorio fue acaparado por las élites económicas que convirtieron la tierra virgen en pastizales listos para el florecimiento de la cría de ganado en las grandes haciendas (Van Ausdal, 2009). Es en este contexto, en que nace la hacienda cómo unidad productiva del terrateniente en detrimento de la dicotomía campesino/dueño de tierra.

La hacienda emerge en el Alto Sinú con características particulares, pero con la constante difusión de las relaciones capitalistas en la ganadería, la agricultura y la exportación. El campesino a comienzos del siglo XX se embarcó en la tarea de obtener títulos de propiedad sobre la tierra, sin embargo, esto se vio obstaculizado por el sistema capitalista que favorecía a los terratenientes y limitaba las posibilidades del campesino a la aparcería y al contrato, el concierto y la matrícula; estas evitaban que el campesino tuviera propiedad absoluta y vitalicia sobre la tierra (Ocampo, 2007). Una cantidad de haciendas, tales como Vallecito (en el Alto San Jorge), Cuba, Centenario y Yucatán (en los alrededores de Montería), Pasacaballos (en el Alto Sinú), Marta Magdalena y la Antioqueña (en los Córdobas y Montería), utilizaron contratos de aparcería y asalariaron jornaleros en la educación de sus tierras para la producción agropecuaria (Escobedo, 2000).

Durante el tiempo que no atendían sus cultivos los campesinos trabajaban como jornaleros en las haciendas con el fin de recibir un salario que les permitiera mantener su "condición de productores independientes" (Fals. 2002). Esta dinámica permitió la movilización o "trashumancia" de la mano de obra a lo largo de la región y el levante de caseríos entre una y otra hacienda. El ritmo laboral del campesino en el Alto Sinú fue de carácter estacional así como en muchas otras zonas de la región Caribe. La inserción de estas zonas al mercantilismo nacional e internacional expandió las bases sostenibles de la hacienda, mediante las redes mercantilistas y comerciales esta subregión se articuló a la región antioqueña y se amplió el radio de receptores de su producción.

De esta manera puede afirmarse que la ganadería fue uno de los productos que en el siglo XX logró integrar la economía de la zona al mercado nacional e internacional, como consecuencia de la instauración de un sistema capitalista organizador y explotador auspiciado por el propio Estado colombiano (Viloria, 2007). De hecho, en el marco de estas economías de enclave se produjeron formas contestatarias por parte de los campesinos atropellados directamente: 
"La tendencia en nuestra región fue marcándose hacia el predominio del jornaleo (remunerado o endeudado) en el campo, es decir, hacia la proletarización rural, tendencia que produjo reacción en las gentes campesinas y voluntad para volver al modo clásico de producción parcelaria. En esta lucha siguen viviendo hasta hoy en sus numerosos aspectos, extendida ahora en todo el área desde las sabanas centrales de Bolívar hasta el Alto Sinú y San Jorge" (Fals, 2002).

Las dinámicas sociales pueden percibirse en la vida diaria de los campesinos adscritos a las labores de la hacienda. El trauma de los procesos económicos mencionados que transformaron la relación hombre-tierra generó la descomposición social del campesinado privilegiando los intereses económicos de los terratenientes (Álvarez, 1999). Inmersos en un proceso de adaptación constante, los campesinos vivían el día a día con la esperanza de mejorar su situación económica; sus conductas aparecieron bajo la fisonomía de la inestabilidad, es decir, ante la imposibilidad de tener títulos de propiedad sobre la tierra aparecieron los trabajos estacionarios a partir de las temporadas de siembra y cosecha, formas de rebusque del pan diario tomando lo que ofrezca el ecosistema, el aguante que es saber esperar para satisfacer necesidades, entre otras (Fals, 2002).

No obstante, la realidad de interdependencias con base en la explotación semiservil que se vivió en las haciendas del Alto Sinú, generó súbitos malestares y descontentos entre los campesinos que adscritos a la hacienda no solo debían entregar su mano de obra, sino también, su filiación política. En el Alto Sinú la mayoría de poblaciones se encontraban sumidas en un camino con un final incierto, donde el diario vivir dependió de los principios de explotación de las haciendas como unidad productiva que solo acumulaba capital para sus dueños. Esto implicaba que por mayor esfuerzo que hicieran los campesinos al trabajar, los hacendados siempre buscarían perpetuar su condición semiservil.

La difusa relación entre políticos y gamonales donde no se sabe quiénes son quienes, y donde no se conocía con claridad los límites de cada uno permitió el violento despojo de los campesinos de sus parcelas y su ganado. Los gamonales consiguieron vías legales y favores políticos que validaron cientos de maniobras para el robo de tierras, clausura de caminos, cambio de cauces de aguas, mandando el ganado a los cultivos ajenos, manteniendo grupos armados privados (Negrette, 2007); todo con el fin de establecer modernos 
regímenes de enclaves ilógicos en una economía que buscaba articularse al sistema económico mundial dirigido por ideologías económicas que no respaldaban este tipo de sistemas económicos arcaicos, donde el trabajador parecía más una mercancía o género producido por la hacienda que un ser humano. A propósito de esta situación el cronista José García Tordecilla hizo un comentario sobre la representación de tales circunstancias en el Alto Sinú:

En pleno siglo XX conocí un horrendo trato y comercio humano, que quien lea estos comentarios, creerá que escribo en sentido humorístico o en hipérbole; mas, lo cierto es que allí era costumbre aceptada y corriente, vender y comprar hombres. Estas infames transacciones, casi siempre se efectuaban entre los llamados patronos o sea personajes que poseían muchos trabajadores y que gozaban de muchas influencias en la Comarca. Cuando alguien de estos desarmados mercachifles quería deshacerse de alguno de sus trabajadores le formulaban una deuda imaginaría bastante alta para poderlo vender haciendo alguna concesión al comprador (García, 1976).

Lo que narra este cronista hace referencia a las formas de explotación laboral presentes en las haciendas donde en compañía de la subordinación constitutiva se desarrollaba la economía local. Este, curiosamente era el contexto socioeconómico que daba sentido a la vida del campesino cuya cotidianidad giraba en torno a las formas de producción que le permitían alimentarse él y su familia. Este oscuro escenario, se repitió de manera sistematica, en varias zonas del Caribe colombiano, entre ellos los montes de María, una región analizada ampliamente por el investigador Javier Hernández, quien plantea respecto al tema que en el universo productivo de la hacienda asociado al cultivo, los campesinos veían más una oportunidad de sostenimiento brindada por el patrono, que una forma de explotación semi servil. Todo esto producto de unas relaciones de poder que expropió al campesino y luego lo sometió a formas de explotación laboral reduciéndolo a simple fuerza de trabajo (Hernández, 2008).

En el Alto Sinú la hacienda se muestra como una unidad política, como estructura de poder articulada a otros poderes de la sociedad, e incluso como escenario de confrontación militar cuyas formas de organización se juegan eventualmente fuera de ella. Un escenario de conflictos colectivos armados y de correlaciones de fuerza de un determinado período de la historia reciente de Colombia: La Violencia (Sánchez, 2000). 
La hacienda en esta zona fue precedida por la existencia de pequeñas y medianas propiedades vinculadas también a la ganadería, que permitieron a la región del Alto Sinú responder a las dificultades que planteaba la región, sobre todo en cuanto al transporte, la escasez de capital y las dificultades en el suministro de mano de obra (Viloria, 2007). Las redes mercantiles articuladas en torno al ganado brindaron soluciones efectivas a estos inconvenientes. Sin embargo, a partir de los años 30 esta zona vive un proceso de concentración de la tierra, por vías de represión y violencia, en manos de gamonales al servicio de las élites políticas (Ojeda, 2004).

\section{Conclusiones}

I Alto Sinú fue una subregión impactada profundamente por las $\checkmark$ últimas etapas de la violencia; por lo tanto, fue escenario del problema J estructural la originó: La crisis agraria. Para el momento en que en el interior del país empiezan a surgir los grupos guerrilleros como las FARC y el ELN, existía una aguda crisis de desigualdad en la distribución de la tierra en esta subregión del Alto Sinú, la cual pedía a gritos ser resuelta a través de alguna reforma agraria que reivindicara la situación de los campesinos despojados de las tierras por los terratenientes.

Al final solo puede recordarse el reducido alcance de las reformas sociales y económicas, y el escenario de represión y persecución presentes en las regiones del país. Con la llegada del Frente Nacional los terratenientes del Alto Sinú legalizaron la persecución contra los campesinos que se resistían a entregar sus tierras, persiguiéndolos por desafiar al Estado bajo la modalidad de lucha guerrillera.

El paisaje actual del Alto Sinú es producto de las apropiaciones y transformaciones de los grandes hacendados con fines de fortalecer su economía particular, la propiedad campesina prácticamente ha desaparecido y estos han tenido que recurrir a los trabajos estacionales en las haciendas para poder alimentarse a sí mismos y a sus familias.

\section{BIBLIOGRAFÍA}

Entrevistas orales.

Alzate, Luis. Ex miembro de la guerrilla. Residente en el municipio de Tierralta.

Jaramillo, Octavio. Campesino de Tierralta. Ex miembro de la guerrilla.

Berrocal, Joaquín. Ex juez municipal de Montería. Escritor, autor del libro: "La colonización antioqueña en el departamento de Córdoba". Residente en Montería. 
Archivos digitales

Gobernación de Córdoba. "Geografía de Córdoba". http://www.cordoba.gov.co/cordoba/ geografia.html.

Informe general Centro Nacional Memoria Histórica. "Los orígenes, las dinámicas y el conflicto armado". Pág. 110- 193. http://www.centrodememoriahistorica.gov.co/descargas/informes2013/ bastaYa/capitulos/basta-ya-cap2_110-195.pdf.

Libros y revistas

Acevedo, Darío. (1998). La mentalidad de las élites sobre la violencia en Colombia (1936-1949). Bogotá: El Áncora Editores/ Universidad Nacional.

CEPAL. Proyecto regional de población Centro Latinoamericano y Caribeño de Demografía (CELADE), División de Población de la CEPAL/Fondo de Población de las Naciones Unida.

Codazzi, Agustin \& Domínguez, Camilo. (1960). Directorio Nacional de Explotaciones Agropecuarias (Censo Agropecuario), Bogotá: DANE.

Escobedo, Rodolfo \& Bottía, Luis. (2000). La violencia en el sur del Departamento de Córdoba. Barcelona: Planeta Colombiana. 2000.

Fals, Borda. (2002). Historia doble de la Costa. Tomo III y IV. Bogotá: Universidad Nacional de Colombia/ Banco de la República/El Áncora.

García, José F. (1976). Causas y efectos de la violencia en el Alto Sinú. Urabá: Hispania.

Guerrero, Fredy. (2009). "Memoria y excepcionalidad en el Alto Sinú. Los límites y alcances de la representación". Trabajo de grado para optar al título de magíster en Estudios Políticos. Pontificia Universidad Javeriana.

Hernández, Javier. (2008). "Formas y modos del trabajo en la hacienda tradicional montemariana (1930- 1960)". Revista Palobra No 9. Cartagena: Universidad de Cartagena. 118: 102 a 125.

IGAC. (1997). Regiones naturales de Colombia [mapa], edición 1997, 1:5000000. Consultado el 4 de agosto del 2014.

Meisel, Adolfo \& Pérez, Gerson. Documentos de trabajo sobre economía regional Geografía física y poblamiento en la Costa Caribe colombiana. Bogotá: Banco de la República.

Molano, Alfredo. (2008). "Viaje al corazón del Alto Sinú". El Espectador, Diciembre 20.

Negrete, Víctor. (2007). Lucha por la tierra y reforma agraria en Córdoba. Montería: Universidad del Sinú.

Ocampo, Gloria. (2007). La instauración de la ganadería en el valle del Sinú: la hacienda Marta Magdalena, 1881- 1956. Medellín: Universidad de Antioquía/ ICANH.

Ojeda, Diana. (2004). "Economía ganadera, ocupación del territorio y conflicto por la tierra en la región del Sinú, 1900-1930”. Tesis de Pregrado. Universidad de los Andes. 
Serje, Margarita. (2005). El revés de la nación. Territorios salvajes y tierras de nadie. Bogotá: Uniandes/Ceso.

Sánchez, Gonzalo \& Peñaranda, Ricardo. (2007). Conflicto armado y crisis política del Frente Nacional en los años 90. Pasado y presente de la violencia en Colombia. Medellín: La carreta Histórica.

Striffler, Luis. (2008). El Alto Sinú. Corporación Autónoma Regional de los Valles del Sinú y San Jorge. Montería: Fundación Universitaria Luis Amigó.

Van Ausdal, Shawn. (2009). "Potreros, ganancias y poder. Una historia ambiental de la ganadería en Colombia, 1850-1950". Historia Crítica. 2009, 137:126 a 149.

Viloria, Joaquín. (2007). "Producción hacendil y parcelaria: los casos de la ganadería, la hacienda de trapiche y el tabaco en la economía regional del Caribe colombiano". En La Región y sus orígenes Momentos de la historia económica y política colombiana. Comp. Bell Lemus Gustavo. Barranquilla: Parque Cultural del Caribe/ Nomus. 61: 59 a 81. 

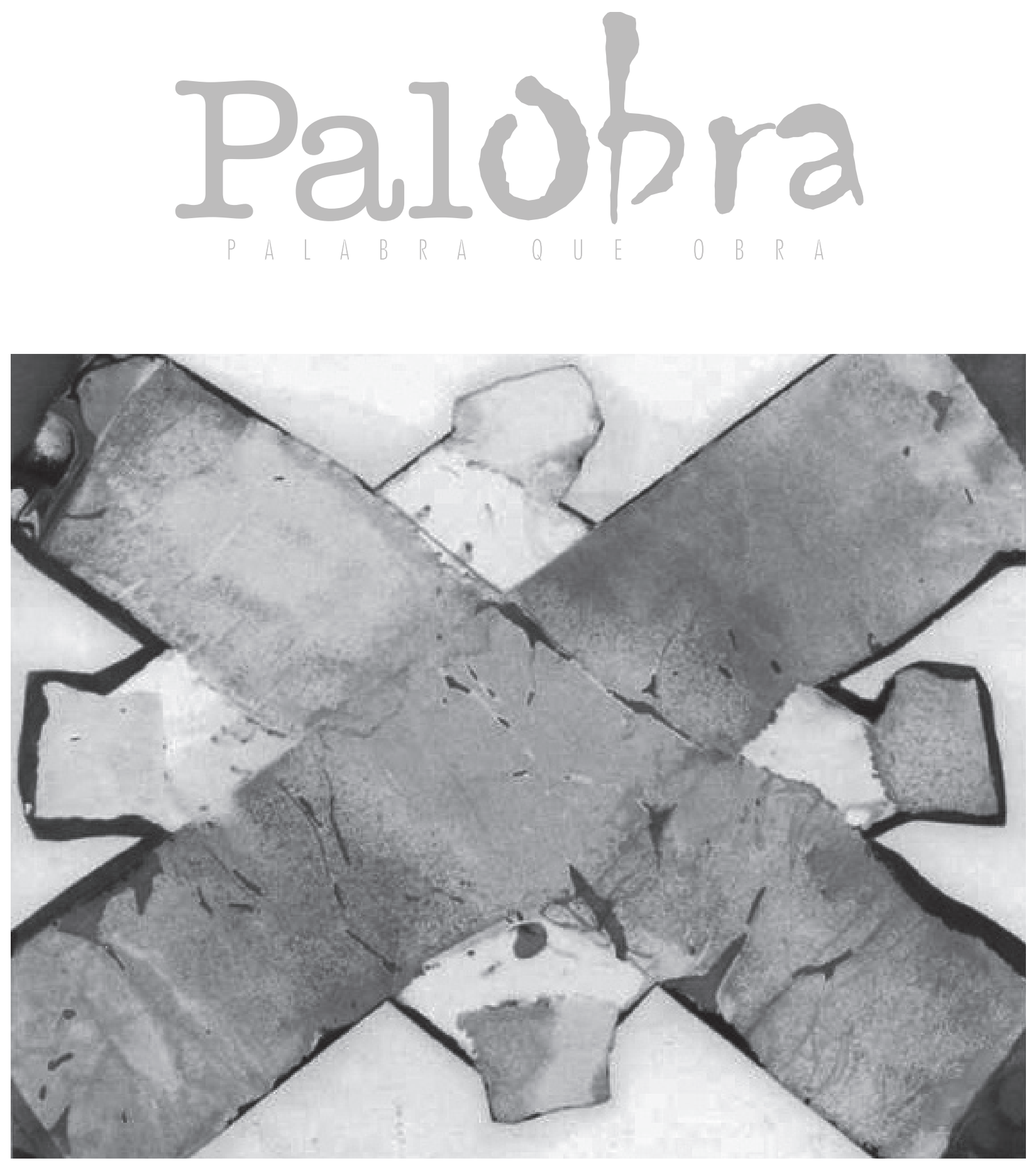

Fotogramas. 1985. Fotografía 